\title{
Removal of nitrogen and phosphorous from domestic wastewater
}

\author{
Artem Kulakov ${ }^{1, *}$, and Nikolay Makisha ${ }^{2, *}$ \\ ${ }^{1}$ Vologda State University, Lenina Street, 15, Vologda, 160000, Russia \\ ${ }^{2}$ Moscow State University of Civil Engineering, Yaroslavskoye Shosse, 26, Moscow, 129337, Russia
}

\begin{abstract}
This work is aimed at providing a deep cleaning from nitrogen and phosphorus at the requirements level for a small capacity waste water treatment plants with active sludge. The wastewater treatment technology includes: mechanical screen, anaerobic reactor, anoxic reactor, two aerobic reactors with floating media, aerobic reactor, clarifier, bioreactor, purification, filter, filter of tertiary treatment with the sorbent, ultraviolet disinfection facility. The sludge treatment includes aerobic stabilizer and facility of mechanical dewatering. The developed technology ensures deep purification of household waste waters from nitrogen and phosphorus. The degree of purification in the ammonium-ion reaches of $99.5 \%$. Efficiency of total nitrogen removal (the sum of ammonium, nitrite and nitrate nitrogen) is $85 \%$. The efficiency of biological purification of phosphates is 97.8 percent that is achieved without the use of coagulant. Requirements are met in most cases.
\end{abstract}

\section{Introduction}

Implementation of advanced wastewater treatment at small treatment plants is a difficult task due to dimensions of the facilities, the irregularity of the composition and volume of sewage [1,2]. There are different effective technologies of removal of nitrogen and phosphorus to major stations [3-7]. However, their adaptation to small structures may be sometimes difficult $[1,8]$.

At the stations of biological purification with active sludge the main task is to ensure effective mixing, aeration and/or mechanical devices. The creation of anaerobic conditions for the biological dephosphotation and anoxic conditions for denitrification processes is the basis how to achieve environmental standards.

Performance improvement of small objects (Figure 1) is required in the formation of biomass in condition of regular load on the facilities by organic and biogenic substances as well as by volume. This work is aimed at providing a deep cleaning from nitrogen and phosphorus at requirements level at a small capacity waste water treatment plants with active sludge.

\footnotetext{
*Corresponding authors: artem.a.kulakov@gmail.com,nmakisha@gmail.com
} 


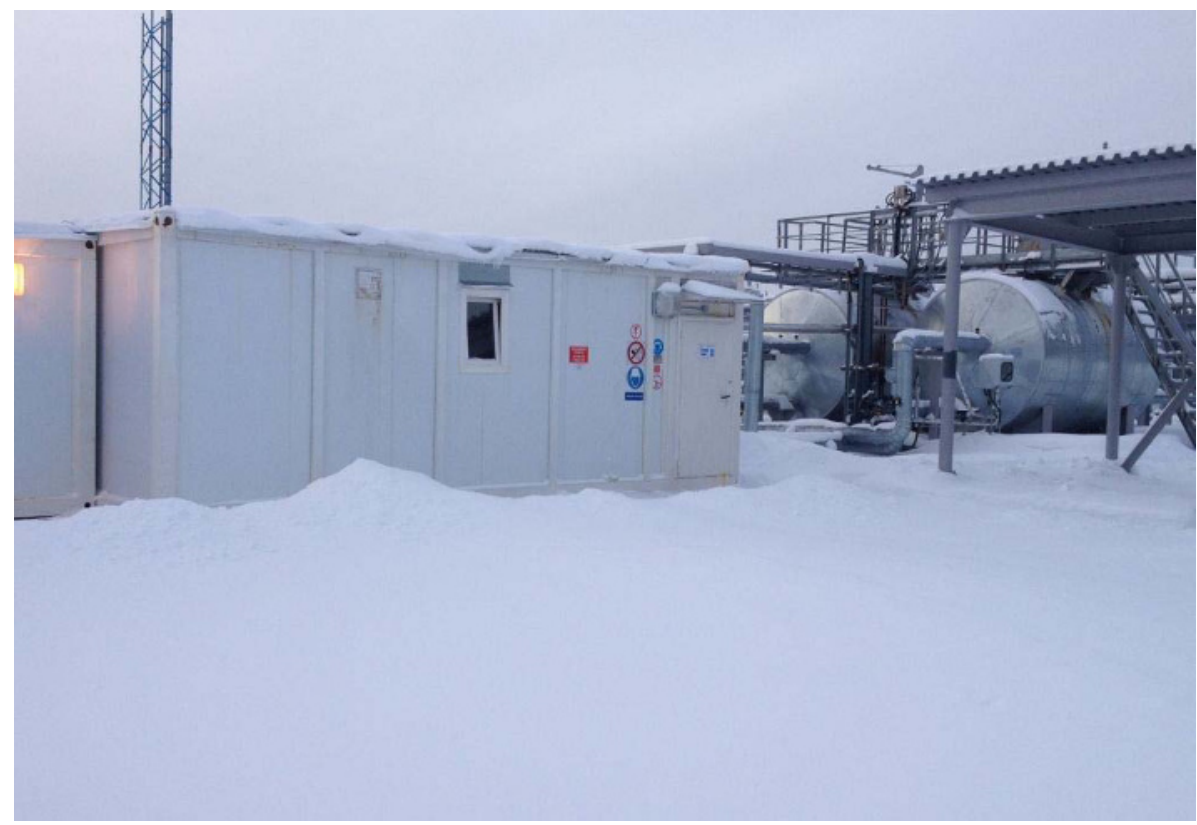

Fig. 1. Waste water treatment plants of small capacity

\section{Methods}

The analyses of wastewater were performed according to standard procedures on certified equipment in the laboratory sewage treatment plant.

The main indicators characterizing the efficiency of domestic wastewater treatment, is as follows:

- $\quad$ Suspended solids (SS).

- Chemical oxygen demand (COD).

- Biochemical oxygen demand $\left(\mathrm{BOD}_{5}\right)$.

- Ammonium-ion $\left(\mathrm{NH}_{4}\right)$.

- $\quad$ Nitrite-ion $\left(\mathrm{NO}_{2}\right)$.

- Nitrate-ion $\left(\mathrm{NO}_{3}\right)$.

- Phosphate-ion $\left(\mathrm{PO}_{4}\right)$.

A total the three nitrogen forms was calculated to assess changes in the content of nitrogen:

$$
\Sigma N=0,78 * \mathrm{NH}_{4}+0,3 * \mathrm{NO}_{2}+0,23 * \mathrm{NO}_{3}, \mathrm{mg} / \mathrm{l} .
$$

Technology correction was based on the methods of process simulation to achieve maximum use facilities' capacity [9-12].

\section{Technology}

Facilities designed for purification of household sewage water of industrial site and residential complex. The volume of treated wastewater varies from 10 to $24 \mathrm{~m}^{3} /$ day., an average flow is $15 \mathrm{~m}^{3} /$ day.

Wastewater is pumped to the treatment facilities by means of sewage pumping stations (Figure 2). Wastewater goes through mechanical screens to remove suspended particles of 
size greater than the size of the grid opening from wastewater, as well as long fibers, sand and grease. Partially cleaned from mechanical impurities wastewater received in the intermediate tank, from which it is evenly pumped to treatment in the biological treatment unit [13-18].

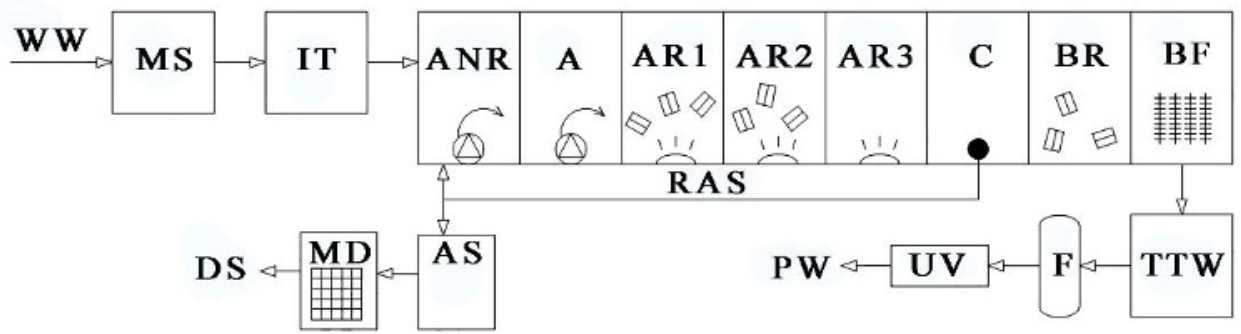

Fig. 2. Technological scheme: MS - mechanical screen, IT - intermediate tank, ANR - anaerobic reactor, A - anoxic reactor, AR1, AR2 - aerobic reactor with floating feed, AR3 -aerobic reactor, C clarifier, BR - bioreactor, BF - biofilter, TTW - tank for biologically treated water, F - filter, UV UV-disinfection, AS - aerobic stabilizer, MD - mechanical dewatering, WW - waste water for treatment, PW - purified waste water, RAS - return active sludge

The first stage of biological treatment is anaerobic reactor (ANR), where it is mixed with circulating activated sludge (CES). Then the sludge mixture enters anoxic tank (A). The liquid mixing in the anaerobic and anoxic tanks is performed by submersible pumps. After anoxic tank the sludge mixture sequentially passes through the three aerobic reactor (AR), equipped with a system of fine-bubble aeration. The first and second AR is equipped with a floating feed for immobilization of biofilms (Figure 3), thus treatment goes by a combination of biomass: free-floating and attached [8, 9, 19-24].
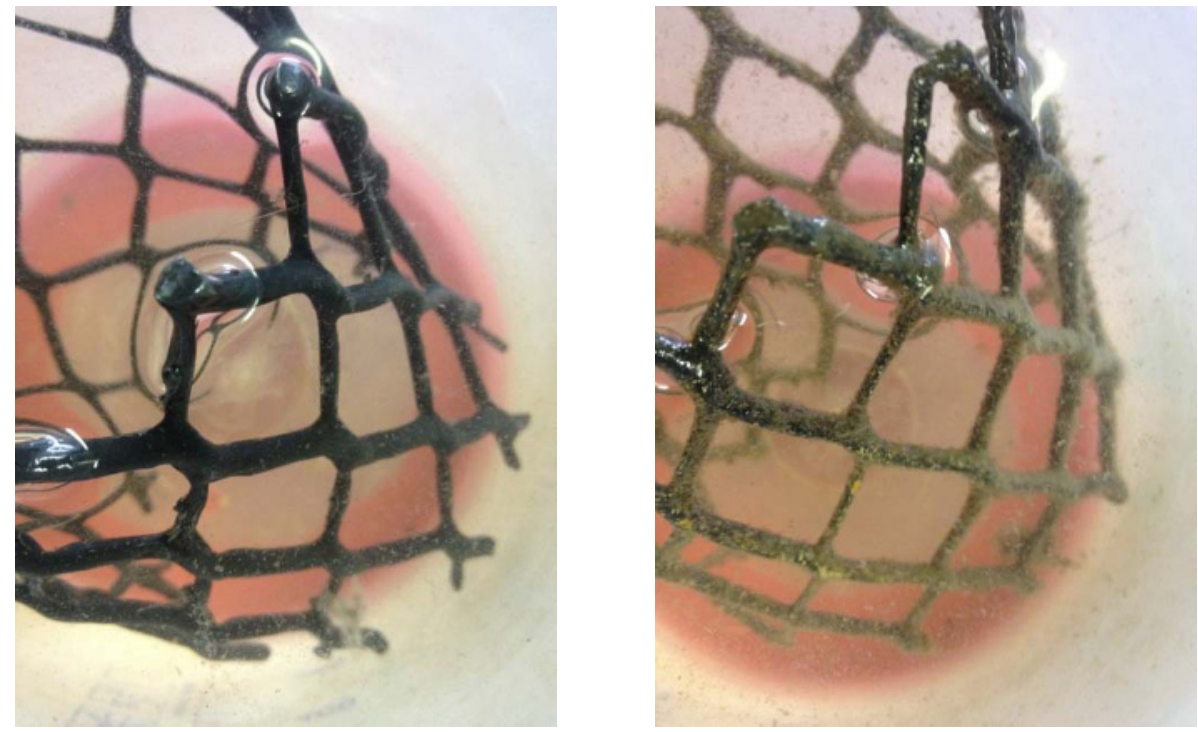

Fig. 3. New bioreactor media (left), bioreactor media with biomass (right)

After aerobic reactors the sludge mixture enters the clarifier where the water is separated from sludge, which is pumped by airlift pumps back to the anaerobic reactor. The clarified water passes through the bioreactor of tertiary treatment with floating load (the same load in aerobic reactors) and biofilter with brush feed to remove fine particles. 
The biologically purified waste water flows into the tank and it is pumped to the filter with sorbent and ultraviolet disinfection. Removal of phosphates can be made by means of coagulant (if necessary). Excess activated sludge is treated in aerobic stabilizer and facility of mechanical dewatering.

\section{Results}

Long observation of the facility work confirmed the stable treatment of wastewater with high efficiency for removal of nitrogen and phosphorus. The concentration of dissolved oxygen determined at different points to evaluate the oxygen regime structures (Table 1).

The conditions with low oxygen is maintained in the anaerobic and anoxic reactors to provide the processes of denitrification and biological phosphorus removal. The concentration of dissolved oxygen in the aeration tanks that is above $2 \mathrm{mg} / \mathrm{l}$ has positive effect on the processes of nitrification [25-28].

The analysis of the content of pollutants in the wastewater showed a high degree of purification on nitrogen and phosphorus and compliance with requirements on them in most cases (Table 2) [29-33].

Table 1. Concentration of dissolved oxygen

\begin{tabular}{|c|c|}
\hline Tank & Value [mg/l] \\
\hline Anaerobic reactor & 0,2 \\
\hline Anoxic reactor & 0,05 \\
\hline Aerobic reactor 1 & 2,2 \\
\hline Aerobic reactor 2 & 4,9 \\
\hline Aerobic reactor 3 & 7,2 \\
\hline Clarifier & 2,5 \\
\hline Bioreactor & 4,5 \\
\hline Biofilter & 6 \\
\hline Tank for treated water & 7,5 \\
\hline
\end{tabular}

Table 2. Concentration of pollutants in waste water

\begin{tabular}{|l|c|c|c|c|}
\hline \multirow{2}{*}{\multicolumn{1}{c|}{ Indicator }} & \multicolumn{2}{c|}{ Concentration [mg/l] } & \multirow{2}{*}{ Efficiency [\%] } & \multirow{2}{*}{ Limits } \\
\cline { 2 - 5 } & In & Out & 98 & 3 \\
\hline Suspended solids & $135-154$ & $2-4$ & 90 & - \\
\hline $\mathrm{COD}$ & $455-515$ & $40-55$ & 97 & 2 \\
\hline $\mathrm{BOD}_{5}$ & $92-115$ & $1,5-3,4$ & 97,8 & 0,6 \\
\hline Phosphate-ion & $6,9-10$ & $0,11-0,3$ & 99,5 & 0,5 \\
\hline Ammonium-ion & $82-90$ & $0,21-0,46$ & - & 0,08 \\
\hline Nitrite-ion & $0,03-0,08$ & $0,12-0,39$ & - & 40 \\
\hline Nitrate-ion & $0,53-0,71$ & $37-46$ & 85 & - \\
\hline$\Sigma \mathrm{N}$ & $64,1-70,4$ & $8,7-11$ & & \\
\hline
\end{tabular}


The analysis of activated sludge sedimentation and structure of activated sludge was carried out (fig.4). The activated sludge has a well-defined structure and a high rate of sedimentation.

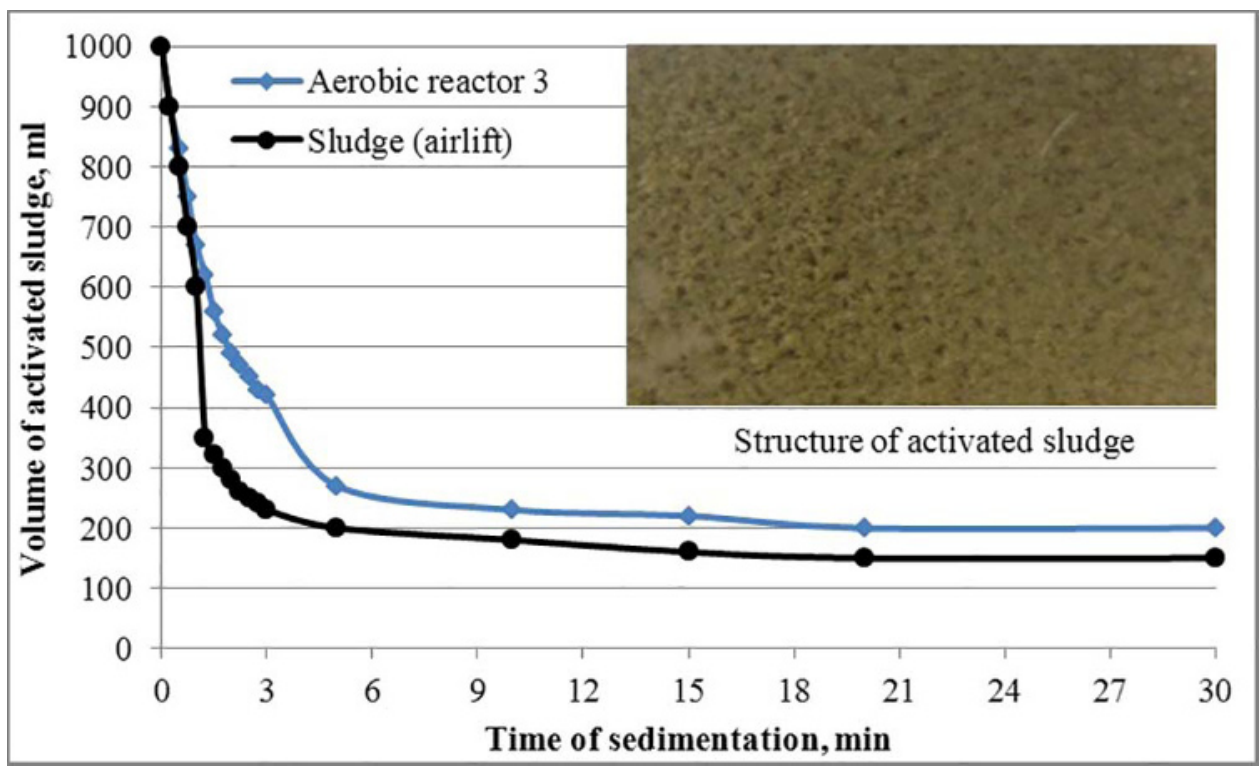

Fig. 4. Sedimentation of activated sludge

Cleaning efficiency in the total of the three nitrogen forms (ammonium, nitrite and nitrate) is $85 \%$, which is also fairly high, that can be obtained by means of strict following of operation procedure (Table 3).

Table 3. Operation procedure

\begin{tabular}{|l|c|}
\hline \multicolumn{1}{|c|}{ Action } & Regularity \\
\hline Visual analysis of immobilized biomass & Daily \\
\hline Visual estimate of mixing efficiency in ANR, A and ARs & Daily \\
\hline Visual control of sludge level in clarifier & Daily \\
\hline Volumetric sludge dose estimate in ANR, A and ARs & Daily \\
\hline Dry compound sludge dose estimate in ANR, A and ARs & Weekly \\
\hline Sludge index calculation & Weekly \\
\hline Determination of dissolved oxygen concentration & Daily \\
\hline Cleaning of tray and walls & Weekly \\
\hline Aeration of biofilter (5-10 min) & Weekly \\
\hline Pumping of excessive sludge & Weekly \\
\hline
\end{tabular}

\section{Conclusions}

1. The developed technology allows providing a deep purification of household waste waters from nitrogen and phosphorus. The degree of purification in the ammonium-ion reaches of $99.5 \%$. In the process of nitrification there is a slight increase in nitrites and nitrates that characterizes the occurrence of denitrification. The effectiveness in the total of the three nitrogen forms (ammonium, nitrite and nitrate) is $85 \%$. The efficiency of biological purification of phosphate make up 97.8 percent, the result is achieved without the use of coagulant. Requirements are met in most cases. 
2. Identified areas for further improvement structures. For increase of efficiency of preliminary mechanical cleaning of large debris and improve the reliability of the pumps required extra grate (sieve) with opening size of $4 \mathrm{~mm}$.

3. Maintaining a high cleaning efficiency is only possible while ensuring proper operation of facilities.

\section{References}

1. A.A. Kulakov, ViST 5, 25-30 (2013)

2. A.A. Kulakov, A.F. Shafigullina, Vodoochistka 8, 28-36 (in Russian) (2016)

3. N. Makisha, V. Scherbakov, A. Smirnov, E. Scherbina, IJAER 10 (24), 44347-44349 (2015)

4. V. Scherbakov, E. Gogina, T. Schukina, N. Kuznetsova, N. Makisha, E. Poupyrev, IJAER 10 (21), 44353-44356 (2015)

5. E. Gogina, I. Gulshin, Pr. Eng. 117, 107-113 (2015)

6. A.G. Pervov, A.P. Andrianov, T.P. Gorbunova, A.S. Bagdasaryan, Petr. Chem. 55 (10), 879-886 (2015)

7. I. Gulshin, A. Kuzina, IJAER 10 (21), 42618-42623 (2015)

8. E.S. Gogina, O.V. Yantsen, O.A. Ruzhitskaya, AMM 580-583, 2354-2357 (2014)

9. O.A. Ruzhitskaya, E.S. Gogina, AMR 919-921, 2141-2144 (2014)

10. A. Volkov, V. Chulkov, R. Kazaryan, M. Fachratov, O. Kyzina, R. Gazaryan, AMM 580-583, 2281-2284, (2014)

11. A.A. Kulakov, Wat.Ecol 1 (61), 26-40 (2015)

12. A.G. Pervov, A.P. Andrianov, E.B. Yurchevskiy, Petr. Chem. 55 (10), 871-878 (2015)

13. O.A. Ruzhitskaya, E.S. Gogina, AMR 919-921, 2153-2156 (2014)

14. Kulakov A.A., Lebedeva E.A., Umarov M.F., EiPR 11, 33-36 (2011)

15. E. Gogina, A. Pelipenko, MATECCONF 73, 03007 (2016)

16. Kulakov A.A., Lebedeva E.A., Vodoochistka 12, 10-19 (2011)

17. V.N. Varapaev, S.A. Doroshenko, A.Y. Trotsko, A.V. Doroshenko, IJAER 10 (21), 42588-42592 (2015)

18. N. Makisha, O. Yantsen, AMM 587-589, 640-643 (2014)

19. O. Kuzina, E. Pankratov, V. Tkachev, MATECCONF 86, 05023 (2016)

20. V. Orlov, A. Andrianov, AMM 580-583, 2398-2402 (2014)

21. N. Makisha, Y. Voronov, E. Poupyrev, V. Volshanik, IJAER 10 (21), 41919-41922 (2015)

22. V.N. Varapaev, A.V. Doroshenko, I.Y. Lantsova, Pr. Eng. 153, 816-823 (2016)

23. N. Zaletova, Y. Voronov, N. Makisha, IJAER 10 (21), 42454-42455 (2015)

24. E.S. Gogina, O.A. Ruzhitskaya, O.V. Yantsen. AMR 919-921, 2145-2148 (2014)

25. N. Makisha, E3sconf 6, 01002 (2016)

26. A.G. Pervov, A.P. Andrianov, DWT 35 (1-3), $2-9$ (2011)

27. E. Gogina, I. Gulshin, AMM 580-583, 2367-2369 (2014)

28. A. Volkov, O. Kuzina, Pr. Eng. 153, 838-843 (2016)

29. N. Makisha, Pr. Eng. 165, 1087-1091 (2016)

30. A.A. Volkov, A.V. Sedov, P.D. Chelyshkov, D.A. Lysenko, A.V. Doroshenko, IJAER 10 (22), 43269-43272 (2015)

31. N. Makisha, Pr. Eng. 165, 1092-1097 (2016)

32. E. Gogina, I. Gulshin, Pr. Eng. 153, 189-194 (2016)

33. A.G. Pervov, A.P. Andrianov, V.A. Chukhin, R.V. Efremov, IJAER 10 (22), $43517-$ 43525 (2015) 